\title{
Processed of Sand Ore Iron Oxide Ferro Low as Raw Steel in Reveberatory Furnace
}

\author{
Wahyono Suprapto \\ Mechanical Engineering, Engineering Faculty, Brawijaya University, MALANG-INDONESIA
}

\begin{abstract}
Sand ore iron with Fe content less than $20 \%$ by weight referred to generally low quality iron ore into a heap material. Sand iron ore with Fe content above $50 \%$ used as pellets or briquettes before it is processed into pig iron in a blast furnace. This paper describes the process of sand agglomeration low Fe iron ore in the reveberatory furnace so worthy of being iron ore pellets. The early stages of this research are the manufacture of raw iron ore pellets at hot isostatic pressing process. Iron ore pellet raw material consists of a main ingredient; iron sand, activated carbon, limestone, and a binder; bentonite, drops, feces. Furthermore, raw iron ore pellets in a furnace reverberatory fuel LPG and coke at $1400^{\circ} \mathrm{C}$ temperature for five hours agglomeration process occurs. The results showed changes in raw pellets into iron nuggets with an iron content up to $53 \%$ and the compressive strength of $35 \mathrm{~kg} / \mathrm{cm}^{2}$.
\end{abstract}

Keywords-sand ore; smelting; reverberatory furnace; pellet; metallic compound

\section{INTRODUCTION}

Iron and other dairy products manufacturing industry is a material that is not replaced by another material. example; mother ships, locomotives and rail, other ground transportation, and use of main battle tank armor. Stretch of sea coast of Java, and almost the entire Indonesian archipelago rich in inorganic materials, especially iron ore with Fe content lower oxides and impurities so small its economic value. Complex compound of iron oxide ore and the lack of smelter technology is one of the obstacles processing of iron ore to metallic iron (pig iron). Chaurasia et al, $2013^{[1]}$, said iron ore with Fe content less than $58 \%$ is not economical as raw material for the steel industry.

High blast furnaces generally 24 to 30 meters and reveberatory furnace usually called water 6 to 8 meters. Blast furnaces require physical pellet impact strength and high porosity because small particles can clog. Reported pellet requirements have not broken Shatter index value of $2.01 \%$ by weight, Abraham et al, $2012^{[2]}$. In addition to the advantages shorter, reveberatory furnaces produce high product efficiency and create a clean environment. Technically Reveberory insulate furnace and flame direct contact with the pellet fuel at high temperature that optimizes the diffusion process. Reveberatory furnace smelting process usually for metallic ores such as copper and zinc. Wahyono et al, 2012 ${ }^{[3]}$, in foundry research duralumin by reveberatory furnace, said gas porosity is not only determined by material elements but is also influenced by the morphology of the results of casting.

Thermodynamically Reveberatory furnace combustion reaction also generates heat directly and centrally thus reducing heat losses both convection and conduction. The combustion heat is used for the reduction reaction $\mathrm{FeO}$ into ferro metallic pellets indicated in the smelting process. The heat loss will increase in direct-indirect combustion and increasing the flow of heat, such as blast furnace. Reveberatory furnaces fuel can use a mixture of gas and solid fuel. Yu et al, 2012 $2^{[4]}$, stated that the reduction of $\mathrm{FeO}$ is relatively tight, the higher the temperature reduction of the volume fraction of $\mathrm{CO}$ that reacts the higher which when reduction $\mathrm{Fe}_{2} \mathrm{O}_{3}$ still ongoing constituent $\mathrm{FeO}$ faster than consumption and after $\mathrm{Fe}_{2} \mathrm{O}_{3}$ surface of the pellets discharged, molarity $\mathrm{FeO}$ down significantly.

Reveberatory furnaces generally use a single fuel; gas, liquid, or solid, and the combination of fuel use can control the element iron nuggets. Carbon in the pellets in the combustion reaction of carbon from a mixture of LPG fuel, coke and pellets do not only consume the oxygen of the combustion air but lowers the oxygen in the pellet through capillary. In reveberatory furnace carbon combustion reaction of gas and solid fuels (LPG and coke) generate very high heat so that the sand iron in pellet clumping urgently oxygen atom. The research objective is to characterization nugget sand iron ore pellets oxide low iron content as raw material for steel and cast iron making industries.

\section{EXPERIMENTAL DETAILS}

The main ingredient pellets are sand ore iron oxide ferro, carbon, lime stone, and adding organic binder are bentonite, mollases, cow feces are $75 \mathrm{wt} \% \mathrm{Fe}_{2} \mathrm{O}_{3}, 10 \mathrm{wt} \% \mathrm{C}, 5 \mathrm{wt} \% \mathrm{CaCO}_{3}$, and binders are $5 \mathrm{wt} \%, 3 \mathrm{wt} \%, 2 \mathrm{wt} \%$ respectively. Molding material pellets of carbon steel hollow cube shape with a length $\mathrm{x}$ width $\mathrm{x}$ height $=9 \mathrm{~cm} \times 9 \mathrm{~cm} \times 14 \mathrm{~cm}$ and a hole diameter of $3.3 \mathrm{~cm}$. The main ingredient and binder average lodged into a mixture of pellets. Furthermore, the mixed material is inserted into the mold and compacted by isostatic pressing (IPing) at a pressure of $150 \mathrm{MPa}, 100{ }^{\circ} \mathrm{C}$, the solidification time of 30 minutes to produced green pellets high is $3.5 \mathrm{~cm}$. Furthermore green sand iron ore pellets tested physically obtained; compressive strength $\sigma_{\mathrm{c}}=28 \mathrm{~N} / \mathrm{mm}^{2}$, porosity of $7.4 \%$ and containing ferro chemicals, carbon, oxygen, and elements of follow-up as in Table 1. Transformation of sand ore iron oxide ferro to sand ore iron green pellet and iron ore red pellet is finally products (Figure 1).

TABLE I. ELEMENT OF SAND ORE IRON GREEN PELLET

\begin{tabular}{|l|l|l|l|l|l|}
\hline \multirow{3}{*}{ Material } & \multicolumn{5}{|c|}{ Elements [wt\%] } \\
\cline { 2 - 7 } & $\mathrm{C}$ & $\mathrm{O}$ & $\mathrm{Na}$ & $\mathrm{Mg}$ & $\mathrm{Al}$ \\
\hline \multirow{3}{*}{$\begin{array}{l}\text { Iron ore } \\
\text { green pellet }\end{array}$} & $\mathbf{1 8 . 8 3}$ & $\mathbf{4 2 . 1 6}$ & $\mathbf{0 . 4 1}$ & $\mathbf{1 . 3 3}$ & $\mathbf{4 . 0 1}$ \\
\cline { 2 - 7 } & $\mathrm{Si}$ & $\mathbf{C a}$ & $\mathrm{Fe}$ & $\mathrm{Ti}$ & Imp \\
\cline { 2 - 7 } & $\mathbf{8 . 1 9}$ & $\mathbf{9 . 7 0}$ & $\mathbf{1 2 . 0 8}$ & $\mathbf{1 . 1 5}$ & $\mathbf{2 . 1 4}$ \\
\hline
\end{tabular}



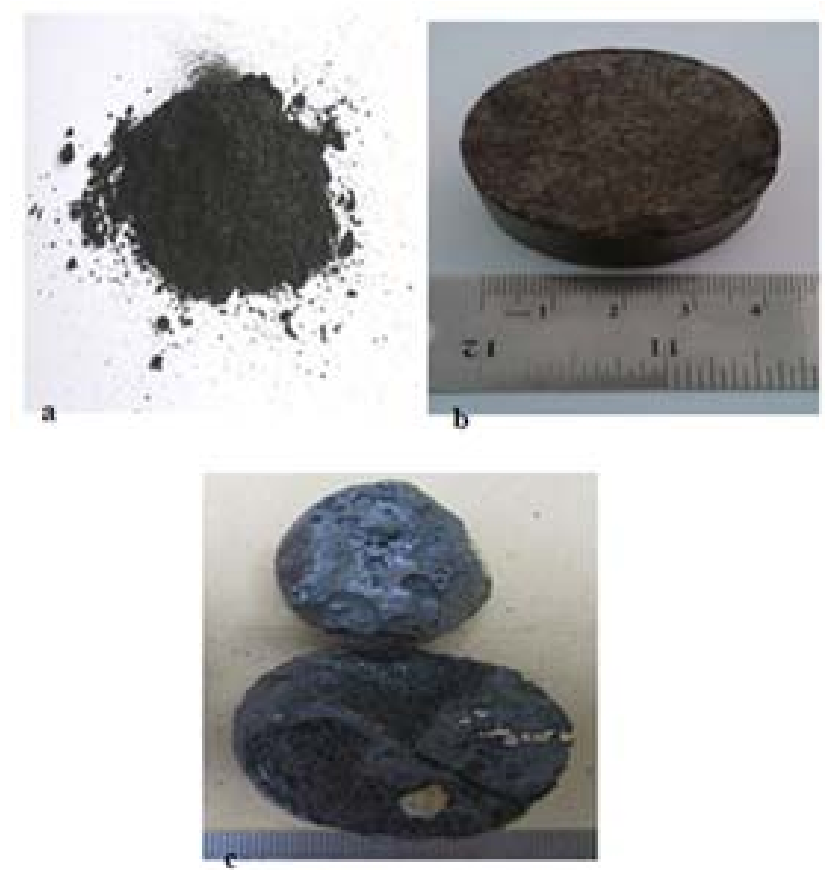

FIGURE I. TRANSFORMATION OF RAW MATERIAL TO IRON ORE PELLET: A) SAND ORE OXIDE IRON, B) SAND ORE IRON GREEN PELLET, C) IRON ORE RED PELLET

The next phase, the green sand iron ore pellets in a furnace reveberatory with a mixture of liquefied petroleum gas (LPG) and coke. Air (oxygen) to the combustion process previously flowed into the fuel economizer so that the air temperature reaches $125^{\circ} \mathrm{C}$. The combustion air is mixed with LPG in the mixing tube and a fired in the burner. LPG combustion flame and hot air is contacted directly to the coke placed in reveberatory furnace. Consumption of fuel and combustion air in the Reverberatory furnace are $5 \mathrm{l} / \mathrm{min} \mathrm{LPG}, 75 \mathrm{~g} / \mathrm{min}$ coke, $10 \mathrm{l} / \mathrm{min}$ of air. Smelting process of green sand iron ore pellets into red iron ore pellets in the reveberatory furnace occurs at a temperature of $1400^{\circ} \mathrm{C}$, respectively for $150,180,210,240$, 300 minutes (as the independent variable). Remove the red iron ore pellets (result agglomeration thermochemical process) of the reveberatory furnace. Furthermore, red iron ore pellets tested chemical elements, porosity, and compressive strength. Use the results can be seen in Table 2. And Figure 2 shows the equipment IPing and reveberatory furnaces used in the study.

TABLE II. ELEMENTS CONTENT OF IRON ORE RED PELLET

\begin{tabular}{|c|c|c|c|c|c|c|c|c|c|c|}
\hline \multirow{2}{*}{$\begin{array}{l}\text { Burning } \\
\text { time } \\
\text { [minutes] }\end{array}$} & \multicolumn{10}{|c|}{ Elements [wt\%] } \\
\hline & $\mathrm{C}$ & $\mathrm{O}$ & $\mathrm{Na}$ & Mg & Al & $\mathbf{S i}$ & $\mathrm{Ca}$ & $\mathrm{Fe}$ & $\mathbf{T i}$ & Imp. \\
\hline 150 & 7.07 & 29.72 & 1.73 & 1.80 & 4.79 & 7.79 & 7.35 & 33.70 & 4.18 & 1.87 \\
\hline 180 & 4.80 & 28.29 & 0.53 & 2.46 & 4.87 & 5.10 & 4.10 & 43.71 & 3.43 & 2.71 \\
\hline 210 & 3.16 & 27.12 & 0.74 & 3.16 & 4.30 & 6.35 & 4.81 & 44.26 & 5.02 & 1.08 \\
\hline 240 & 0.91 & 25.43 & 0.41 & 2.22 & 5.65 & 6.49 & 5.65 & 47.86 & 4.09 & 1.29 \\
\hline 300 & 1.47 & 24.54 & - & 2.72 & 4.71 & 4.41 & 3.53 & 53.18 & 4.65 & 0.79 \\
\hline
\end{tabular}

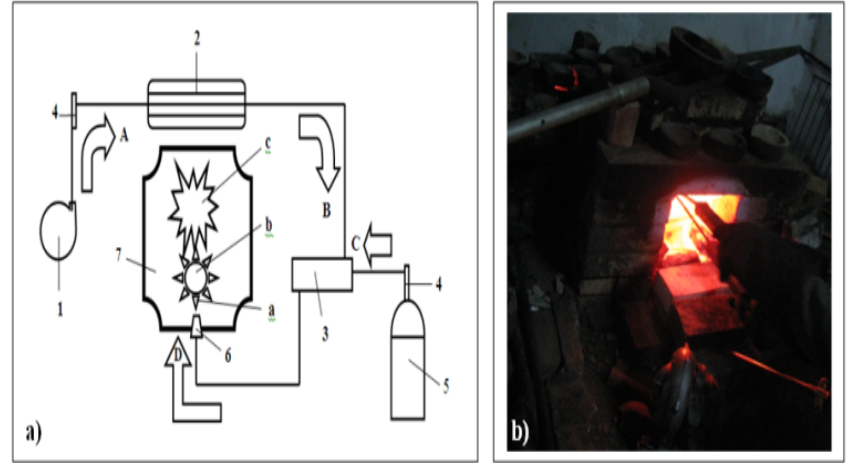

FIGURE II. THERMAL GENERATION OF REVEBERATORY FURNACE IN RESEARCH: A) SCHEME OF REVEBERATORY FURNACE, B) BURNING IN SMELTING PROCESS

\section{RESULTS AND DISCUSSION}

\section{A. Physical Properties}

Red iron ore pellets which has been produced generally kind and nature must be preserved during storage, transport and combustion processes (pyrolysis). Mechanically red iron ore pellets have a compressive strength ranges from 200-300 N per pellet $\approx 39$ to $59 \mathrm{~N} / \mathrm{mm} 2$ and achieve $18 \%$ porosity. The process of reduction and oxidation reactions (redox) in smelted furnaces steel and cast iron determined by the quality of red pellet iron ore as raw material. Some requirements of red iron ore pellets quality including; ferrous content above $50 \%$, high compressive strength, and porous. During the process agglomerisasi, the dimensions of the green pellets is reduced as shown in Fig. 1, this shows that the density and porosity of red pellets respectively increased and decreased. Tensile, compressio and shear strengths the solid material is generally determined by its physical properties, and increasing time agglomerizasion then compression strength of the red pellet increases.

During the burning of limestone, dolomite, and molasses in $\mathrm{Fe}_{2} \mathrm{O}_{3}$ form a liquid phase that serves as driving force (binder) and after cold give contribute to the strength of the pellets. Moisture content feces and molasses in the combustion process through capillary leaving pellets and leaving small cavities or porosity consequently increased porosity pellets. And evaporation of the liquid phase on the surface of the pore forming a thin layer of oxide compounds are hard and porous. According to Vilas, 2010 ${ }^{[5]}$, microstructure of the sintered pellets revealed that the porosity and formation of liquid phase affects the compressive strength of the pellets, metal oxide grains during cooling of also influences the strength of the pellets and its metallurgical properties. Tests such as tumbler and shatter tests give an indication of the material behaviour during ore mining, loading, transportation, handling, and screening. They also give an insight into the material's behaviour, during an initial period of the reduction process in its descent in the furnace. Iron ore is determined by using cold strength testing.

The testing data of optical emission spectrometry (OES), chemical composition of raw materials (sand ore iron green pellet ) and sand ore iron red pellet as in Table 1 and Table 2. 
The table shows the increase in weight $\% \mathrm{Fe}$ in the red iron pellets due to two phenomena; 1). direct reduction reaction and 2). capillarizasion oxygen by high temperature. Carbon in LPG and coke as a reductant to consume. Determination of the theoretical density of pellets due to the weight equilibrium $\%$ of elements in the pellets which is formulated as follows:

$$
\gamma_{T}=\frac{\sum \% u \cdot \gamma u}{100}=\frac{\% u_{1} \cdot \gamma u_{1}+\% U_{2} \cdot \gamma u_{2}+\ldots \ldots+\% u_{n} \cdot \gamma u_{n}}{100}
$$

where, $\mathrm{u} \%$ and $\gamma$ both are show the percentage $\%$ chemical element, and density. Testing porosity (Picnometry) of pellets refers to Archimedes law and weight to volume dimension of ore iron pellet. From Picnometry test ASTM Standard B311-93, which porosity (quantitative) is the ratio of the red iron ore pellets difference density (theoretical-red pellets) and theoretical density is chemical contents by $100 \%$, mathematically are formulated:

$$
P=\frac{\gamma_{\text {theoritical of pellet }}-\gamma_{\text {red pellet }}}{\gamma_{\text {theoritical of pellet }}} \times 100 \%
$$

$\gamma_{\text {castdural }}$ are taken from the measurements of the specimen weight in the air $\left(\mathrm{W}_{\mathrm{a}}\right)$, specimen weight + bucket in water $\left(\mathrm{W}_{\mathrm{sb}}\right)$, buckets weight in water $\left(\mathrm{W}_{\mathrm{b}}\right)$, then the result of that weight measurements are mathematically operated as follows:

$$
\gamma_{\text {redpellets }}=\frac{W_{a}}{W_{a}-\left(W_{s b}-W_{b}\right)} x \gamma_{w}
$$

where $\gamma_{\mathrm{w}}$ : the density of distilled water. From the measurement and operation of equations 1,2, and 3 we obtained the data in graphical form (Figure 3a).

\section{B. Mass Balance Analysis}

Table 2 shows Smelting processes that occur in the various time 150-300 minutes describe reducibility elements of reductant $(\mathrm{C})$, oxidizing $(\mathrm{O})$ and impurities (adverse) that combine the green iron ore pellets. Mutual reducibility of carbon and oxygen in the pellet bodies by high temperature combustion reaction caused the element Fe increased. High temperature combustion atmosphere outside the body increases the coefficient of diffuse pellet thus transform the elements carbon and oxygen from the body pellet into flames leaving the Fe elements. In the iron ore processing, high reducibility is a key determinant to improve the transformation of ferro elements into metallic iron in the manufacture of red iron ore pellets. Vilas, $2006^{[6]}$, states formation of magnesio ferrite and high melting point slag with low $\mathrm{FeO}$ content in the fired pellets could be attributed to the improved performance of pyroxenite pellets.

Thus the concentration operation of eq. 1 determines the transformation of green pellets into $\mathrm{Fe}_{3} \mathrm{O}_{4}$ with an indication of the elements $\mathrm{Fe}$ increases, naturally the elements $\mathrm{Ti}$ is increased. The presence of $\mathrm{Ti}$ in iron minerals will certainly limit the maximum content of $\mathrm{Fe}$ element. Each increment $\mathrm{Fe}$ will be followed by a rise of Ti element. Finally operations, Fe concentration can be increased to about 58 to 61 percent of the Ti content of about 3 to 5 percent. This is due to its high oxygen affinity than ferro carbon and titanium, as shown in Figure $3 b$.

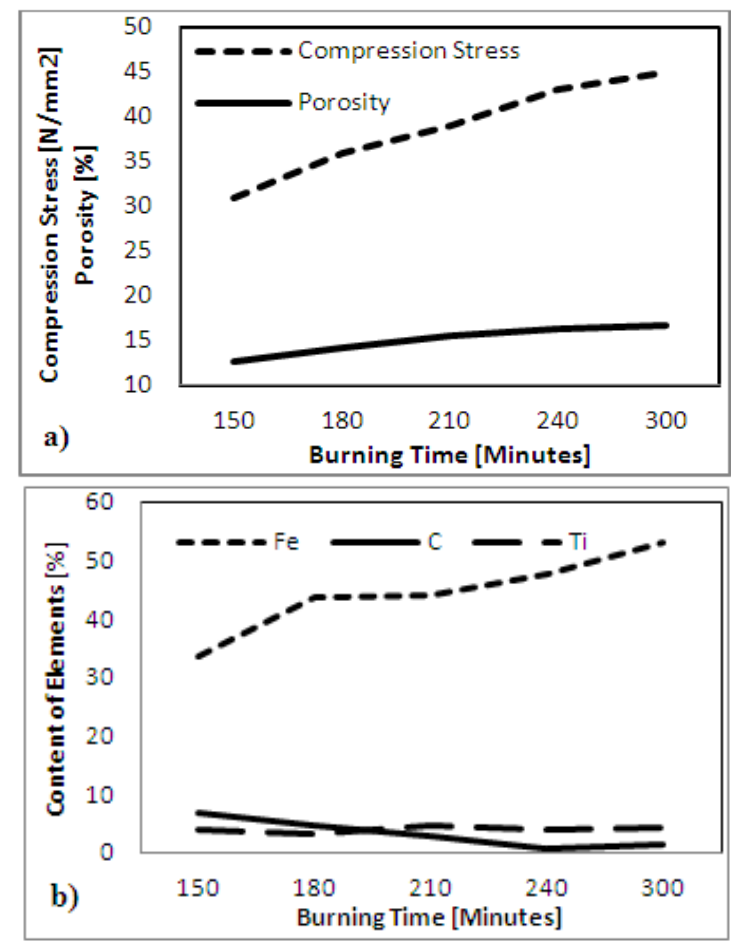

FIGURE III. THE CHARACTERIZATION OF RED IRON ORE PELLET:

A) MECHANICAL AND METALLURGICAL, B) CHEMICAL

This stage occurs at the reaction between oxygen contained in the air with a compound contained in the Green pellets. High temperatures in the combustion process, the water content and the compounds are flammable disengaged. With this excess oxygen originally iron mineral magnetite $\left(\mathrm{Fe}_{3} \mathrm{O}_{4}\right)$ can be transformed into hematite $\left(\mathrm{Fe}_{2} \mathrm{O}_{3}\right)$. The automated mass balance system was configured to calculate the mass and metallurgical balance, reconciling mass and iron content in the production and in the feed, Rodrigo $(2013)^{[7]}$.

After this stage of induration produced pellets that have mechanical properties and metallurgical needed, such as; strength and high porosity $\left(\sigma_{\mathrm{c}}=45 \mathrm{~N} / \mathrm{mm} 2\right.$ and porosity $=$ $7.4 \%$ ). Increasing these properties will improve the combustion process, because pellets can withstand the pressure and weight of the fuel gas, and create a network of capillary oxygen. Dmitriev, 2013 ${ }^{[8]}$. the porosity of materials substantially defines the reducibility. The porosity of agglomerates changes depending on the different factors from 25 up to $45 \%$ at a wide range of the pore sizes. Equilibrium reaction element in the conventional method of burning green pellets is expressed as follows:

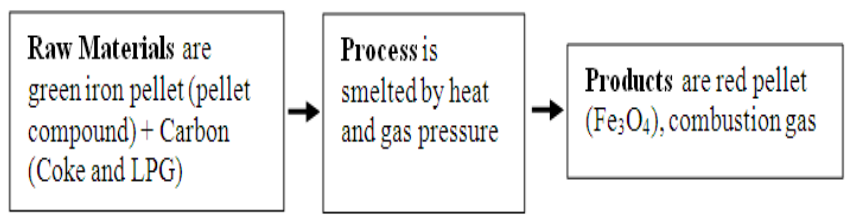

FIGURE IV. SCHEME OF IRON PELLET 


\section{Thermo Analysis}

Hydrocarbon combustion reactions generally produce carbon monoxide $\left(\mathrm{CO}_{(\mathrm{g})}\right)$ and carbon dioxide $\left(\mathrm{CO}_{2(\mathrm{~g})}\right)$, the content of $\mathrm{CO}_{(\mathrm{g})}$ and $\mathrm{CO}_{2(\mathrm{~g})}$ is determined by the availability of air as an oxygen source. The combustion process can (rebeberatory) needs air is very limited and the consumption of fuel by preheating the air so that efficient heat increases. And incomplete combustion reaction when insufficient oxygen to form $\mathrm{CO}_{2(\mathrm{~g})}$ and water. It also happens when the combustion is quenched by a heat sink, such as a solid surface or flame trap. Stoichiometric reaction of formation of $\mathrm{CO}_{2(\mathrm{~g})}$ in pellet on the Redox reactions in reveberatory is formulated

$$
\begin{aligned}
& \mathrm{C}_{(\mathrm{S})}+\mathrm{CO}_{2(\mathrm{~g})} \rightarrow 2 \mathrm{CO}_{(\mathrm{g})} \\
& \mathrm{O}_{2(\mathrm{~g})}+2 \mathrm{CO}_{(\mathrm{g})} \rightarrow 2 \mathrm{CO}_{2(\mathrm{~g})}
\end{aligned}
$$

Formation of combustion of carbon monoxide gas in the reverberatory furnace due to limited oxygen in the combustion air preheat LPG with oxygen triggers green pellets flow out. Generally mechanism and to produce Carbon-dioxide like combustion pushing for capillary out as shown in the reaction eq. 1 and eq. 2. During the sinter process the atoms of the element will diffuse from high concentration to low concentration. In this case the pellet containing concentrations of carbon and oxygen is higher than flame combustion. And the degree of homogenization depends on the diffusion coefficient is determined by the temperature. And homogeny time defined by the equation: $t_{p}=\frac{a^{2}}{4 \pi D}\left[\frac{\pi C_{o} p}{6 C_{a}(1-p)}\right]^{2 / 3}$

where, $\mathrm{a}=$ diameter of the alloying particles, $\mathrm{D}=$ diffusion coefficient, $\mathrm{Co}=$ initial concentration of the alloying element in the dispersed alloying particles (usually 100\%), $\mathrm{Ca}=$ average concentration of the alloying element in the base metal, $\mathrm{p}=\mathrm{Cmin} / \mathrm{Cmax}=$ degree of homogenization.

Combustion reaction mixture with the high temperature combustion air and combustion gas coke to fuel the burning of LPG mixture of fuel and air preheat produce high temperature $\left(1400^{\circ} \mathrm{C}\right)$. Measurements high-temperature furnace combustion chamber reveberatory done with infra red Model Nr: DS 300, Serie : 0396969-30, Azeige : $10850 \mathrm{Hi}: 1800$. Sintering process that occurs at a temperature of $1400^{\circ} \mathrm{C}$ with holding time more than 150 minutes causes the particles of green iron ore pellet to transformation thermo-chemical in the form of lumps of intermetallic red pellets so that the it strength is increases. Increasing the temperature of the combustion chamber to raise the rate of diffusion of oxygen and carbon green pellets as shown in eq. 7. From the diffusion process causes the two elements carbon and oxygen in red pellets is reduced as the process decarburising on steel.

Table 2 shows a decrease in the elements carbon and oxygen in the experiment. Burning with simultaneously high air temperatures generate high thermal efficiency and reduce the formation of $\mathrm{CO}$ and $\mathrm{NO}_{\mathrm{x}}$ emissions, so that the peak flame temperature increased, Ellul et al, 2007 $7^{[9]}$. Magnetite or hematite concentrates typically have an ultra-fine size distribution, for example $80 \%$ passing $45 \mu \mathrm{m}$. This material cannot be used directly in the blast furnace and is also problematic in sinter production, so it is normally used in the manufacture of pellets. According to Höganäs, 2013 ${ }^{[10]}$, the iron ore must have a suitable size distribution or specific surface area $\left(\mathrm{m}^{2} / \mathrm{g}\right.$ or "Blaine index") to form good pellets. In some cases the ore will already be at a suitable size after beneficiation. If not, further grinding is required. Magnetite concentrates undergo oxidation to hematite during firing, and form bonds at lower temperatures than do hematite concentrates, substantially decreasing the fuel requirements of the firing process, Honeyands, 2012 ${ }^{[11]}$. Thermoanalysis shows that all Muko iron ores exhibit endothermal and exothermal effects below $700^{\circ} \mathrm{C}$ and above $1100^{\circ} \mathrm{C}$, respectively, Abraham et al. $(2012)^{[12]}$. The endothermal peaks observed in the Ug1$\mathrm{Ug} 5$ samples in the temperature range $365-632{ }^{\circ} \mathrm{C}$ are due to the transformation of $\gamma$-hematite (maghemite) to $\alpha$-hematite. The absence of the $\gamma$ - $\alpha$-hematite phase transition in the Ug6 sample is due to the larger content of chemically bonded water (goethite and $\mathrm{Fe}_{2} \mathrm{O}_{3}$ hydrate), which when dissociated leaves only $\alpha$-hematite phase.

\section{CONCLUSIONS}

1. Combined fuel burning LPG and coke in a reverberatory furnace can chemically alter an average content of elements $(\mathrm{Fe}, \mathrm{C}, \mathrm{O})$ and mechanical properties average $(\sigma \mathrm{c}, \mathrm{P})$ green pellets become red pellets each of $12,08 \% \mathrm{Fe}, 18.83 \% \mathrm{C}$, $42.16 \% \mathrm{O}$ becomes $44.5 \% \mathrm{Fe}, 3.45 \% \mathrm{C}, 27.0 \% \mathrm{O}$ and 17.5 $\mathrm{N} / \mathrm{mm}^{2}, 7.4 \%$ to be $38 \mathrm{~N} / \mathrm{mm}^{2}, 15 \%$.

2. Increasing time green pellet burning chemical elements and mechanical properties of red pellets increases, gradient highest increase occurred in the burning time of 300 minutes with the specifications of chemical elements: $53.18 \% \mathrm{Fe}$, $1: 47 \% \mathrm{C}, 24.54 \% \mathrm{O}$ and the mechanical properties of 45 $\mathrm{N} / \mathrm{mm}^{2}, 16.8 \%$.

\section{ACKNOWLEDGMENTS}

This research was financially supported by the competition research of Brawijaya University by contract Number: 060/PHK/UB/PKD/Contract/2015.

\section{REFERENCES}

[1] Varsha Chaurasia, Piyush Kant Pandey, Ranjan Halda, TechnoEconomical Viability Of Integrated Beneficiation With Pellet Plant Fitting To DRI Technology - A Model For Future Economics, International Journal of Advanced Engineering Research and Studies EISSN2249-8974, IJAERS/Vol. II/ Issue II/Jan.-March.,2013/08-10.

[2] Abraham J. B. Muwanguzi, Andrey V. Karasev, Joseph K. Byaruhanga, and Pär G. Jönsson, Characterisation of the Physical and Metallurgical Properties of Natural Iron Ore for Iron Production, ISRN Materials Science, Volume 2012 (2012), Article ID 147420, 9 pages.

[3] Wahyono S, B. Suharno, Johny WS, Dedi P, Morphology and Quantity of Gas Porosity as the result of Duralumin Cast on Reveberatory Furnace, International Journal of Material Engineering and Technology, Vol. 8, No. 2, 2012, p. 123-135.

[4] Yu-liang Wu, Ze-yi Jiang, Xin-xin Zhang, Peng Wang, and Xue-feng She, 2012, Numerical Simulation of Pellet's Direct Reduction in Rotary Hearth Furnace for Zinc-containing Metallurgical Dust Treatment, International Journal of Minerals, Metallurgy and Materials.

[5] Vilas Tathavadkar, Srinivas Dwarapudi, Tamal K. Ghosh, Amitabh Shankar, Vilas Tathavadkar, D. Bhattacharjee, R. Venugopal, Effect of pyroxenite flux on the quality and microstructure of hematite pellets, International Journal of Mineral Processing - INT J MINER PROCESS , vol. 96 , no. 1 , pp. 45-53, 2010. 
[6] Vilas Tathavadkar, Veerendra Singh and S. Mohan Rao, Study of Liquid Phase Formation during the Sintering of Chromite Pellets and its Effect on the Properties of Pellets, Proceedings of the International Seminar on Mineral Processing Technology - 2006, Chennai, India. pp. 431 - 435.

[7] Rodrigo Cesar de Miranda, Marco Aurélio Soares Martins, Hugo Montalvão Gontijo, línio Cruz Gianeli, and Bruna Torres Negreiros Cordeiro Andrade, Application of Automatic Mass Balance in Metal Accounting of Iron Ore Plant, ournal of Environmental Science and Engineering A 2 (2013) 127-134, Formerly part of Journal of Environmental Science and Engineering, ISSN 1934-8932.

[8] A.N. Dmitriev, G.Yu. Vitkina, Yu.A. Chesnokov, R.V. Petukhov, Iron Ore Materials and Coke Quality Characteristics and Quantitative Indicators of Blast Furnace Smelting, Conference Paper, August 2013, DOI: 10.3182/20130825-4-US-2038.00025.

[9] C.Ellul, M.Pourkashanian, A.Williams and K.A.M Rabea, Effects of Fuel Composition in High Temperature Air Combustion, Proceedings of The European Combustion Meeting 2007.

[10] Honeyands Tom And Jelenich Lou, Calculating The Value Of Iron Ores In Ironmaking And Steelmaking, Presented at the Asia Steel International Conference, September 2012, Beijing.

[11] Höganäs PM-school, Material and powder properties, General Aspects The sintering process is governed by the following parameters: • temperature and time, (C) Copyright Höganäs AB, December 2013, 263 83 Höganäs, Sweden. 